\title{
Controversy About Pseudo-Kümmell’s Disease
}

To the Editor:

The authors of this manuscript attempt to coin the term "pseudo-Kümmell's" by virtue of an intra-operative observation during a vertebral augmentation procedure. Their suppositions and implications are not supported by the evidence they present in the manuscript, and could adversely impact the understanding of the anatomy, physiology, and surgical technique by those who have less experience employing vertebroplasty. Three issues; vertebroplasty risks and cement leaks, indications for vertebroplasty, and the physical action of pumping air into a vertebral body, as mentioned in the manuscript, are deserving of comment.

The authors accurately list, but only gloss over the contraindications to vertebroplasty. It appears the authors marginalize pre-existing literature that reveals that vertebroplasty is associated with significant risks including cement leaks up to $70 \%$ of the time, causing nerve root compression, cement embolization to the lungs, and even monomer related respiratory and cardiac depression leading to death (1-6). In a similar manner, the authors do not adhere to the indications for vertebroplasty. Indeed, they describe how this patient was not a candidate for traditional surgical intervention by virtue of her debilitated state, anatomic alignment, and bone retropulsed into the spinal canal. They however fabricate a new term "high risk vertebroplasty" for which they imply she was a candidate.

From a biomechanical standpoint, it has been established that vertebroplasty makes no attempt to restore the height of the collapsed vertebral body (7). It is also well established that some height restoration can be achieved simply by positioning the patient prone on bolsters (8). In the case of "Kümmell's," "Dynamic Mobility," or a "true pseudoarthrosis," the positioning will open the gap and effectively appear as a cystic cavity. The implications of this report are very dangerous. The fact that air entered the vertebral body establishes this as an unrecognized pseudoarthrosis which expanded by the mechanics of the prone position as well as exposure to atmospheric pressure after cannulation.

From a physiologic standpoint, this manuscript raises another disturbing issue related to the pumping of air into the vertebral body. Venous air embolism is well documented in the spinal surgery literature. A negative intra-thoracic pressure with inspiration increases the venous return and with the venous sinuses of the vertebral body exposed pumping air into the vertebra may result in a life threatening venous air embolism. This action of pumping air into a vertebral body can in no way be justified on the basis of known physiology.

The fact that the patient sustained no adverse reaction consequent to injecting air and cement into a vertebra plana with retropulsed bone into the canal does not create or justify an indication for vertebroplasty under these conditions. The fact that the authors observed air in a gap in the vertebral body does not justify the introduction of a new descriptive term of "pseudo-Kümmell's."

\section{REFERENCES}

1. Cotton A, Boutry N, Cortet B et al. Percutaneous vertebroplasty: State of the art. Radiographic 1998; 18:311-320.

2. Deramond H, Depriester C, Galibert P et al. Percutaneous vertebroplasty with polymethylmethacrylate. Technique, indications, and results. Radiol Clin North Am 1998; 36:533-546.

3. Heini PF, Walchli B, Berlemann U. Percutaneous transpedicular vertebroplasty with PMMA: Operative technique and early results. A prospective study for the treatment of osteoporotic compression fractures. Eur Spine J 2000; 9:445-450.

4. Jensen ME, Evans AJ, Mathis JM et al. Percutaneous polymethylmethacrylate vertebroplasty in the treatment of osteoporotic vertebral body compression fractures: Technical aspects. $A m$ J Neuroradiol 1997; 18:1897-1904.

5. Martin JB, Jean B, Sugiu K et al. Vertebroplasty: Clinical experience and follow-up results. Bone 1999; 25:S11-S15.

6. Padovani B, Kasriel $O$, Brunner $P$ et al. Pulmonary embolism caused by acrylic cement: A rare complication of percutaneous vertebroplasty. Am J Neuroradiol 1999; 20:375-377.

7. Belkoff SM, Mathis JM, Fenton DC et al. An ex-vivo biomechanical evaluation of an inflatable bone tamp used in the treatment of compression fracture. Spine 2001; 26:151-156.

8. McKiernan F, Jensen R, Faciszewski T. The dynamic mobility of vertebral compression fractures. J Bone Min Res 2003; 18:24-29.

Anthony T. Yeung, MD, MBA, FRCS(C)

Orthopedic Endoscopic Spine Surgeon

Squaw Peak Surgical Facility

1635 East Myrtle Avenue., Suite 400

Phoenix AZ 85020

E-mail: dryeung@sciatica.com

Isador H. Lieberman, MD, FRCS.(C)

Dept. of Orthopaedic Surgery (A41)

The Cleveland Clinic Foundation

9500 Euclid Avenue

Cleveland, Ohio 44195

E-mail: lieberi@ccf.org 